\title{
Research at the Unit of Lung and Allergy research at Karolinksa Intitutet, Stockholm, Sweden
}

\author{
Congress Chair Award, sponsored by the European Respiratory Society
}

\section{Kjell Larsson}

Karolinska Institutet, National Institute of Environmental Medicine, Division of Physiology, Lung and Allergy Research, Stockholm, Sweden

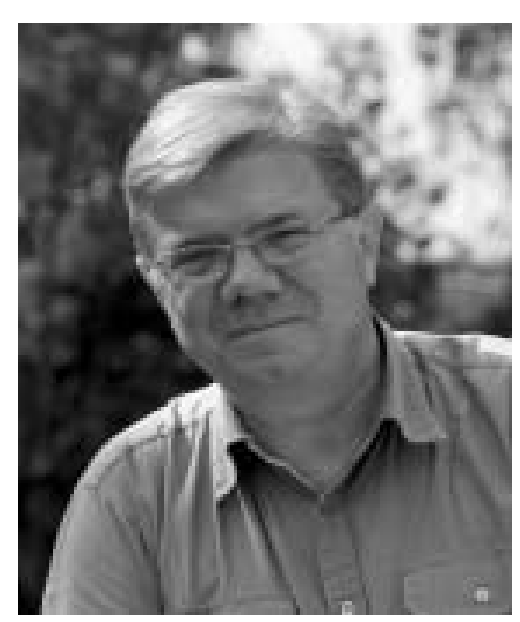

n 2002, the Unit of Lung and Allergy Research moved from the National Institute for Working Life, which was a government research institute separate from the university, to the National Institute of Environmental Medicine at the Karolinska Institutet, which is the medical university of Stockholm, Sweden. The Unit of Lung and Allergy Research group was established at the beginning of the 1980s under the guidance of Professor Per Malmberg and the main interest at that time was within respiratory physiology. At the beginning of the 1990s, the focus changed and became more concentrated on airway inflammatory mechanisms in respiratory diseases, especially as a consequence of exposure to organic material.

\section{RELATIONSHIP TO PIGS: STUDIES OF INNATE IMMUNITY}

It was soon established that exposure in pig barns constitutes a very powerful pro-inflammatory stimulus [1, 2], which enabled us to use exposure to organic dust from pig barns as a model for induction of inflammatory reactions. During the past $15 \mathrm{yrs}$, $\sim 60$ original publications based on in vivo and in vitro experiments of the pro-inflammatory effects of exposure to organic dust and gases from swine confinement buildings have

STATEMENT OF INTEREST: None declared. been published. Six PhD students have defended their theses based on the model and two PhD students are presently working with different aspects of it. After having demonstrated that working for some hours in a pig house causes an intense airway inflammatory reaction and an increase of bronchial responsiveness to methacholine of three to four dose steps, our work has concentrated on characterising the reaction in more detail. We found that exposure of healthy subjects induces a 100fold increase in neutrophils (but no alteration of eosinophils), a two- to three-fold increase of lymphocytes and alveolar macrophages, and a multi-fold increase in pro-inflammatory cytokines and arachidonic acid metabolites, as assessed in lavage fluid from upper and lower airways. Interestingly, we could show that acute exposure in healthy subjects increases bronchial responsiveness to direct stimuli (methacholine, histamine), whereas no such increase was found to an indirect stimulus (dry air hyperpnoea) [3]. Another interesting finding was that the increase in bronchial responsiveness following exposure is not altered by inhaled glucocorticosteroids, disodium cromoglycate or a leukotriene synthesis inhibitor, although some of these drugs substantially altered cellular and mediator responses [4-6]. We also demonstrated that swine-confinement workers, who are exposed to the pig barn environment on a daily basis, have an attenuated response to acute exposure with less increase of bronchial responsiveness and inflammatory markers following exposure than naïve healthy subjects [7]. The mechanisms for this development of tolerance are currently being studied at our laboratory under the direction of Associate Professor Lena Palmberg.

\section{RELATIONSHIP TO FURRED ANIMALS: STUDIES OF ACQUIRED IMMUNITY}

Another area of interest to us has been allergy and allergic sensitisation to laboratory animals and cats, with particular focus on laboratory animal workers and school children. One of our $\mathrm{PhD}$ students showed that airborne levels of cat allergen in classrooms were not altered by measures usually recommended, such as removal of curtains, upholstery and plants, replacing bookshelves and increased cleaning, but by the use of schoolspecific clothing $[8,9]$. The unit has also contributed to the debate about the relationship between the exposure to cats and dogs and the development of asthma and allergy $[10,11]$. It was found 
that heredity of allergy is of considerably lower importance than heredity of asthma for the development of asthma [12].

At present, a prospective, longitudinal study of newly employed laboratory animal workers and personnel working with laboratory animals is on going under the supervision of Associate Professor Anne Renström. The employees are followed for 2 yrs and sensitisation to laboratory animals and the effect of preventive interventions are studied.

\section{RELATIONSHIP TO SMOKERS: STUDIES OF CHRONIC OBSTRUCTIVE PULMONARY DISEASE}

During the last few years, the research at our laboratory has become more focused on chronic obstructive pulmonary disease (COPD). In collaboration with dentists, psychologists, microbiologists and cardiologists, different aspects of COPD are studied. Co-variation between COPD and parodontitis is currently being studied in smokers, and inflammatory mechanisms in the mouth and lungs are compared; microbial agents, known to be of importance for the loosening of teeth, are being sought in the mouth and lungs. Together with psychologists (Professor Emeritus Gunnar Borg), we are making an attempt to find a new symptom index that could be used in clinical practice and trials, and, together with cardiologists, we are investigating cardiac function in smokers with and without COPD. In our laboratory, we are using our experience from the pig barn studies in order to better understand the innate immune reactions in smokers, in particular in those with COPD. At present we have four PhD students working on the project. This project is in an early phase and no publications have appeared so far.

\section{RELATIONSHIP TO THE POPULATION: EPIDEMIOLOGICAL STUDIES}

Two large-scale population studies, as follows, are headed by Associate Professor Bo Lundbäck: 1) the Obstructive Lung Disease in Northern Sweden (OLIN) studies, in progress since 1985; and 2) the FinEsS Studies, in progress since 1996. The OLIN studies are mostly longitudinal and are based on representative samples of the general population. The aims include incidence, remission and relapse of asthma, and allergy and COPD and their determinants. Several cohorts, from school children to elderly subjects, are under study, and, in total, the cohorts include $>50,000$ subjects living in the northernmost county of Sweden, which comprise $25 \%$ of the area of Sweden.

The FinEsS studies, which also focus on the epidemiology of obstructive airway diseases and allergy, are comparative studies of areas in Finland, Estonia and Sweden, including the capitals, Helsinki, Tallinn and Stockholm. New cohorts were recruited in 2006, and the total study sample now exceeds 100,000 subjects. The epidemiological network includes several countries, from the USA in the west to Vietnam and Indonesia in the east.

A key result of the OLIN studies is that $\sim 50 \%$ of the smokers develop COPD. These studies were also among the earliest publications of incidence of COPD. It was shown that, from the age of $40 \mathrm{yrs}$, the incidence of COPD in smokers is 1-2 out of 100 per year, while it was 1-2 out of 1,000 per year among nonsmokers [13, 14]. It was also demonstrated that start of smoking (before the age of $20 \mathrm{yrs}$ ) considerably increases the risk of developing COPD; the risk of $1 \mathrm{yr}$ earlier starting of smoking exceeds smoking of 1 pack $\cdot \mathrm{yr}^{-1}$ as an adult [15].
In health economy assessment, based on population studies, the societal costs of COPD were estimated to be $\sim € 1$ billion per year for Sweden as a whole [16].

In asthma studies, it has been shown that, in contrast to asthma in children, remission of asthma in adults is low, at $<1 \%$ per year [17], although severity of asthma varies considerably over time [18]. The unit has further contributed to the debate of obesity and asthma [19], since obesity has been highly related to incident asthma, verified by the methacholine test in both males and females and allergic and nonallergic subjects [20].

\section{REFERENCES}

1 Larsson K, Eklund A, Hansson L-O, Isaksson B-M, Malmberg P. Swine dust cause intense airways inflammation in healthy subjects. Am J Respir Crit Care Med 1994; 150: 973-977.

2 Larsson K, Malmberg P, Eklund A. Alterations in bronchoalveolar lavage fluid but not in lung function and bronchial responsiveness in swine confinement workers. Chest 1992; 101: 767-774.

3 Sundblad B-M, Palmberg L, Larsson K. Bronchial responsiveness to eucapnic hyperventilation and methacholine following exposure to organic dust., Chest 2002; 122.

4 Ek A, Palmberg L, Larsson K. The effect of inhaled fluticasone on the airway inflammatory response to organic dust. Eur Respir J 2004; 24: 1-7.

5 Larsson B-M, Kumlin M, Sundblad B-M, Larsson K, Dahlén S-E, Palmberg L. Effects of 5-lipoxygenase inhibitor zileuton on airway responses to inhaled swine house dust in healthy subjects. Respir Med 2006; 100: 226-237.

6 Larsson K, Larsson B-M, Sandström T, Sundblad B-M, Palmberg L. Disodium cromoglycate attenuates pulmonary inflammation without influencing bronchial responsiveness in healthy subjects exposed to organic dust. Clin Exp Allergy 2001; 31: 1356-1368.

7 Palmberg L, Larsson B-M, Malmberg P, Larsson K. Airway responses of healthy farmers and non-farmer to exposure in a swine confinement building. Scand J Work Environm Health 2002; 28: 256-263.

8 Karlsson A-S, Andersson B, Renström A, Svedmyr J, Larsson K, Borres M. Airborne cat allergen reduction in classrooms that use special school clothing or ban pet ownership. J Allergy Clin Immunol 2004; 113: 1171-1177.

9 Karlsson A-S, Renström A, Hedrén M, Larsson K. Allergen avoidance does not alter airborne cat allergen levels in classrooms. Allergy 2004; 59: 661-667.

10 Perzanowski MS, Ronmark E, Platts-Mills TA, Lundback B. Effect of cat and dog ownership on sensitization and development of asthma among preteenage children. Am J Respir Crit Care Med 2002 1; 166: 696-702.

11 Ronmark E, Perzanowski M, Platts-Mills T, Lundback B. Four-year incidence of allergic sensitization among schoolchildren in a community where allergy to cat and dog dominates sensitization: report from the Obstructive Lung Disease in Northern Sweden Study Group. J Allergy Clin Immunol 2003; 112: 747-754.

12 Bjerg A, Hedman L, Perzanowski MS, Platts-Mills T, Lundbäck B, Rönmark E. Family history of asthma and atopy: in-depth analyses of the impact on asthma and wheeze in 7- to 8-year-old children. Pediatrics 2007; 120: 741-748. 
13 Lindberg A, Jonsson AC, Ronmark E, Lundgren R, Larsson LG, Lundback B. Ten-year cumulative incidence of COPD and risk factors for incident disease in a symptomatic cohort. Chest 2005; 127: 1544-1552.

14 Lundback B, Lindberg A, Lindstrom M, et al. Not 15 but $50 \%$ of smokers develop COPD? Report from the Obstructive Lung Disease in Northern Sweden Studies. Respir Med 2003; 97: 115-122.

15 Kotaniemi J, Sovijärvi A, Lundbäsck B. Chronic obstructive pulmonary disease in Finland: prevalence and risk factors. COPD 2005; 3: 331-339.

16 Jansson SA, Andersson F, Borg S, Ericsson A, Jonsson E, Lundback B. Costs of COPD in Sweden according to disease severity. Chest 2002; 122: 1994-2002.
17 Ronmark E, Jonsson E, Lundback B. Remission of asthma in the middle aged and elderly: report from the Obstructive Lung Disease in Northern Sweden study. Thorax 1999; 54: 611-613.

18 Ronmark E, Lindberg A, Watson L, Lundback B. Outcome and severity of adult onset asthma: report from the obstructive lung disease in northern Sweden studies (OLIN). Respir Med 2007; 101: 2370-2377.

19 Nathell L, Jensen I, Larsson K. High prevalence of obesity in asthmatic patients on sick leave. Respir Med 2002; 96: 642-650.

20 Ronmark E, Andersson C, Nystrom L, Forsberg B, Jarvholm B, Lundback B. Obesity increases the risk of incident asthma among adults. Eur Respir J 2005; 25: 282-288. 